\title{
37. GEOTHERMAL MEASUREMENTS AT DEEP SEA DRILLING PROJECT SITE 5871
}

\author{
Roger H. Morin, Massachusetts Institute of Technology \\ and \\ Richard P. Von Herzen, Woods Hole Oceanographic Institution ${ }^{2}$
}

\begin{abstract}
A new WHOI heat flow instrument was successfully used in conjunction with the hydraulic piston corer to obtain temperature-time records for three depths at DSDP Site 587. In order to arrive at an estimate for in situ, steady-state temperature, these data are applied to a two-dimensional theoretical formulation that describes the cooling behavior of an annular cylinder surrounded by sediment. An average heat flow of $56.9 \mathrm{~mW} / \mathrm{m}^{2}$ is computed from the resulting temperature profile. This value is in close agreement with the theoretical heat flux of $53.0 \mathrm{~mW} / \mathrm{m}^{2}$ determined from the general heat flow-age relationship. The temperature profile at Site 587 is nonlinear. Examination of the effects of sudden changes in bottom water temperature and upward movement of pore fluid fails to provide convincing solutions to the cause of this nonlinearity. Knowing sediment permeability and extending the theoretical data analysis to three dimensions would improve our ability to understand the geothermal environment at this location.
\end{abstract}

\section{INTRODUCTION}

The Leg 90 scientific program focused primarily on paleoenvironmental studies, requiring extensive use of the hydraulic piston corer (HPC) at several sites traversing tropical to subantarctic regions of the southwest $\mathrm{Pa}$ cific. A new heat flow instrument, developed at the Woods Hole Oceanographic Institution (WHOI), had originally been designed to be deployed with the HPC and provide information regarding the in situ temperature of the sediment column. This tool was initially tested on Leg 86, and its use was incorporated into the Leg 90 schedule because of the possibility of obtaining detailed temperature profiles in conjunction with the planned HPC operations.

The previous method of determining the geothermal gradient involved the separate lowering of temperaturemeasuring instrumentation (Yokota et al., 1980), with the entire process taking between 1 and 2 hours, depending upon the water depth and operating conditions. The new instrumentation employs a thermistor/microprocessor package that is inserted directly into the wall of the HPC cutting shoe, as shown in Figure 1, recording temperature values at preselected time intervals during the coring operation. With this innovative device, the measurement technique is incorporated directly into the coring procedure and determines the in situ temperature, requiring minimum additional operating time ( $\leqslant 10 \mathrm{~min}$.).

Thus, a comprehensive heat flow program was planned for this cruise in conjunction with the ambitious HPC work scheduled along the Lord Howe Rise. Regrettably, one such instrument package had been lost during Leg 89 , which left only one remaining aboard ship. This tool was subsequently lost during a coring malfunction at Site 590 . Hence, the entire heat flow program was lim-

\footnotetext{
${ }^{1}$ Kennett, J. P., von der Borch, C. C., et al., Init. Repts. DSDP, 90: Washington (U.S. Govt, Printing Office).

2 Addresses: (Morin, Von Herzen, present address) U.S. Geological Survey, Denver, CO
}

ited to the geothermal measurements determined at Site 587. These data are presented and analyzed in this chapter.

\section{THEORETICAL FORMULATION}

The heat flow device measures the temperature inside the coring shoe wall as a function of time. Figure $2 \mathrm{~A}-\mathrm{C}$ depicts the temperature-time records obtained at DSDP Site 587, where temperature values have been recorded every $10 \mathrm{~s}$. These include the temperature of the seawater inside the drill string as the HPC was lowered into the hole. A temperature spike in these plots is caused by frictional heating during HPC sediment penetration. The initial rapid increase to a maximum temperature is followed by a relatively undisturbed decay and, finally, by a sudden deviation from this cooling curve as the piston corer is extracted and returned to the ship. The heat flow instrument package was typically placed in the cutting shoe at every fourth HPC deployment, roughly every $36 \mathrm{~m}$. It was allowed to remain imbedded in the sediment for approximately $10 \mathrm{~min}$. before retrieval to obtain a record of the conductive dissipation of heat to the surrounding sediments.

Horai (personal communication) has investigated, both analytically and numerically, the problem of radial conduction through an annular coring shoe surrounded by sediment. This two-dimensional formulation provides a method of processing the transient record of heat dissipation by fitting to a theoretical temperature decay. The theoretical cooling curve is uniquely determined by the thermal properties and dimensions of the coring shoe material and the adjacent marine sediment. Since the piston corer is retrieved from the ocean bottom before an equilibrium temperature can be reached, this procedure allows extrapolation of the decaying temperature record to yield an estimate for the steady-state in situ sediment temperature.

Thermal conductivity values obtained from various depths at Sites 587 and 588 are reported by Morin (this volume). These data are graphically presented here as 


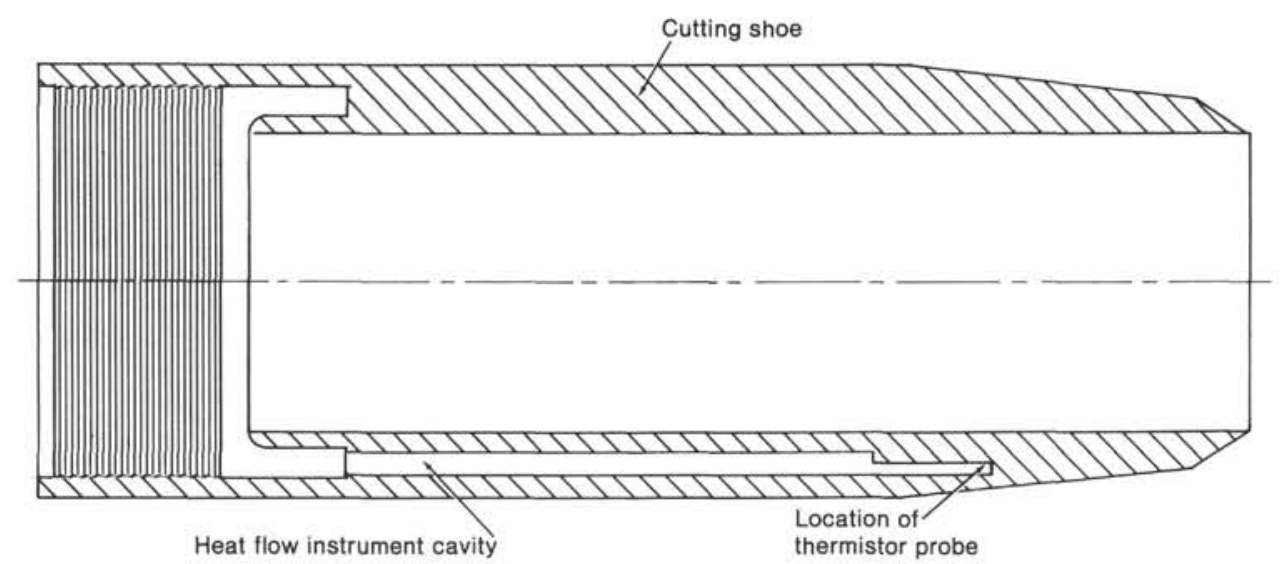

Figure 1. Cross-sectional view of HPC cutting shoe with cavity for heat flow instrument.

well (Fig. 3) and are listed in Table 1. Chaney et al. (1983) describe the experimental technique. Relevant shipboard conductivity measurements were corrected for in situ pressure as suggested by Morin and Silva (1984). The magnitude of the correction is a function of porosity and can differ appreciably from that suggested by Ratcliffe (1960) when low-porosity sediments are exposed to substantial hydrostatic pressures. Because of the relatively shallow water depth of $1100 \mathrm{~m}$ at Site 587, however, the pressure correction determined by either method proved to be quite small (see Appendix). A temperature coefficient, appropriate within a range of 0 to $30^{\circ} \mathrm{C}$, was also applied to the conductivity values determined aboard ship (Macdonald and Simmons, 1972). This adjustment (reduction) to the shipboard thermal conductivity necessitated by the colder in situ temperature was slightly offset by the small adjustment (increase) to the shipboard measurement caused by the larger in situ pressure (see Appendix). The resulting total correction, a net reduction in thermal conductivity of $2.63 \%$, was employed in computing the proper thermal property values necessary to the theoretical heat transfer formulation.

The corresponding values of sediment thermal diffusivity were estimated by the following linear relationship (Von Herzen and Maxwell, 1959):

$$
k=(3.66 K-0.70)\left(10^{-7}\right)
$$

where $K$ is the thermal conductivity and $k$ is the thermal diffusivity in units of $\mathrm{W} / \mathrm{m}^{\circ} \mathrm{C}$ and $\mathrm{m}^{2} / \mathrm{s}$, respectively. Horai's (personal communication) analysis incorporates the following parameters.

$$
\begin{gathered}
K_{\mathrm{HPC} \text { iron alloy }}=25.3 \mathrm{~W} / \mathrm{m}^{\circ} \mathrm{C} \\
k_{\mathrm{HPC} \text { iron alloy }}=10.9 \times 10^{-6} \mathrm{~m}^{2} / \mathrm{s} \\
K_{\text {sediment }}=1.06-1.39 \mathrm{~W} / \mathrm{m}^{\circ} \mathrm{C} \\
k_{\text {sediment }}=3.18-4.39 \times 10^{-7} \mathrm{~m}^{2} / \mathrm{s} \\
\mathrm{HPC} \text { inside diameter }=6.198 \mathrm{~cm} \\
\mathrm{HPC} \text { outside diameter }=9.068 \mathrm{~cm}
\end{gathered}
$$

In this analytical study of the heat transfer across a composite circular cylinder, the initial temperature of the coring shoe is assumed to be both constant and uniform. In actuality, however, the HPC commonly has an uneven temperature distribution at the instant of sediment penetration. Because of this nonuniform condition, the first few data points, or time steps, recorded by the temperature sensor after penetration are expected to deviate from the predicted values ( 1 time step $=10 \mathrm{~s})$. In his analysis, Horai has adjusted for the effect of an ambiguous time origin by including a zero-time offset. The theoretical temperatures with shifted time origin are fitted to the recorded data by minimizing the misfit (error), calculated as the rms value:

$$
\text { error }=\left[\sum^{n} \frac{\left(T_{i}-T_{t i}\right)^{2}}{n}\right]^{1 / 2}
$$

where $T_{i}$ is the observed temperature, and $T_{t i}$ is the theoretical temperature.

\section{TEMPERATURE RESULTS}

Figure $4 \mathrm{~A}-\mathrm{C}$ displays the results of the three downhole temperature measurements obtained at Site 587 . These plots focus upon the decay-curve portions of the data presented in Figure 2. The points represent the temperatures measured by the WHOI instrumentation at 10-s intervals during the coring operation, and the solid lines represent best-fit cooling curves derived from Horai's theoretical analysis in conjunction with the relevant sediment thermal conductivity measurements. The fitting is excellent at a depth of $31.9 \mathrm{~m}$ (Fig. 4A), as evidenced by the relatively small residual error, computed from the least-squares analysis to be 0.008 . Horai's solution demonstrates that, after $600 \mathrm{~s}$ of undisturbed cooling, approximately $78 \%$ of the total expected thermal decay has occurred, and an in situ temperature of $6.42^{\circ} \mathrm{C}$ is calculated.

The second temperature-time record (Figs. 2B and $4 \mathrm{~B})$ at a sub-bottom depth of $70.3 \mathrm{~m}$ shows a disturbance in the thermal decay curve occurring approximately $100 \mathrm{~s}$ after HPC penetration. This slight temperature increase is probably caused by movement that has gen- 

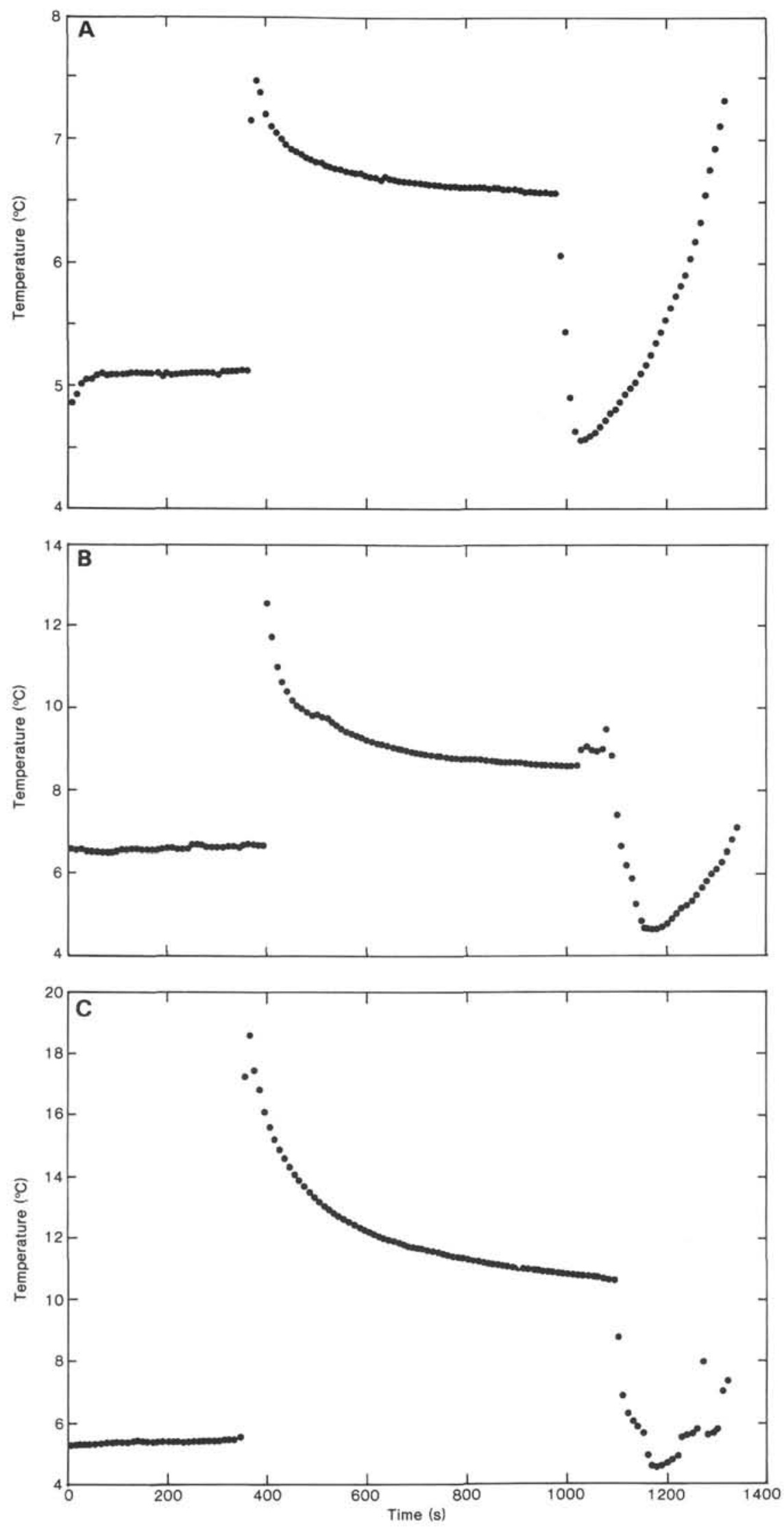

Figure 2. Temperature-time record from WHOI instrument at A. $31.9 \mathrm{~m}$ depth, B. $70.3 \mathrm{~m}$ depth, C. $108.7 \mathrm{~m}$ depth. 


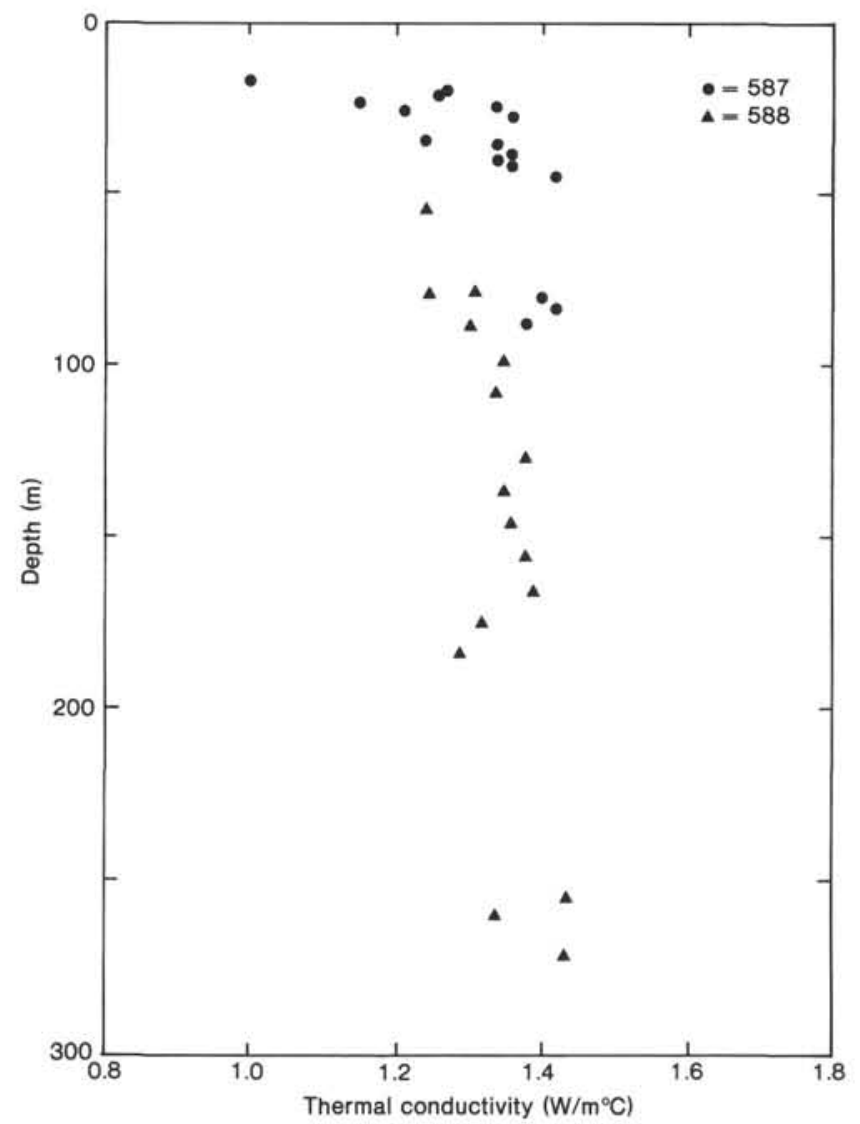

Figure 3. Plot of sediment thermal conductivity (Sites 587 and 588) versus depth.

Table 1. List of sediment thermal conductivity values versus depth for Sites 587 and 588 .

\begin{tabular}{ccccc}
\hline \multicolumn{2}{c}{ Site 587} & & \multicolumn{2}{c}{ Site 588} \\
\cline { 1 - 1 } \cline { 5 - 5 } $\begin{array}{c}\text { Depth } \\
(\mathrm{m})\end{array}$ & $\begin{array}{c}\text { Thermal } \\
\text { conductivity } \\
\left(\mathrm{W} / \mathrm{m}^{\circ} \mathrm{C}\right)\end{array}$ & & $\begin{array}{c}\text { Depth } \\
(\mathrm{m})\end{array}$ & $\begin{array}{c}\text { Thermal } \\
\text { conductivity } \\
\left(\mathrm{W} / \mathrm{m}^{\circ} \mathrm{C}\right)\end{array}$ \\
\hline 16.4 & 1.00 & & 53.9 & 1.24 \\
19.4 & 1.27 & & 78.8 & 1.31 \\
20.9 & 1.26 & & 87.8 & 1.30 \\
23.0 & 1.15 & & 98.0 & 1.35 \\
24.5 & 1.34 & & 107.5 & 1.34 \\
26.0 & 1.21 & & 126.8 & 1.39 \\
27.5 & 1.36 & & 136.3 & 1.35 \\
34.1 & 1.24 & & 146.0 & 1.36 \\
35.6 & 1.34 & & 155.5 & 1.38 \\
38.6 & 1.36 & & 165.2 & 1.40 \\
40.1 & 1.34 & & 174.8 & 1.32 \\
42.2 & 1.37 & & 184.3 & 1.29 \\
45.2 & 1.42 & & 254.9 & 1.44 \\
80.6 & 1.40 & & 260.4 & 1.34 \\
83.6 & 1.42 & & 271.6 & 1.44 \\
88.1 & 1.39 & & \\
\hline
\end{tabular}

erated additional frictional heating. Movement could have been produced by ship motion transmitted through the drill string or simply from settling of the coring gear in the sediment. Horai's analysis is applied to the actual data at the onset of this disturbance in order to achieve a representative fit to the decay curve and, again, a small residual error of 0.008 is calculated. The steady-state temperature at this depth is estimated to be $8.00^{\circ} \mathrm{C}$.
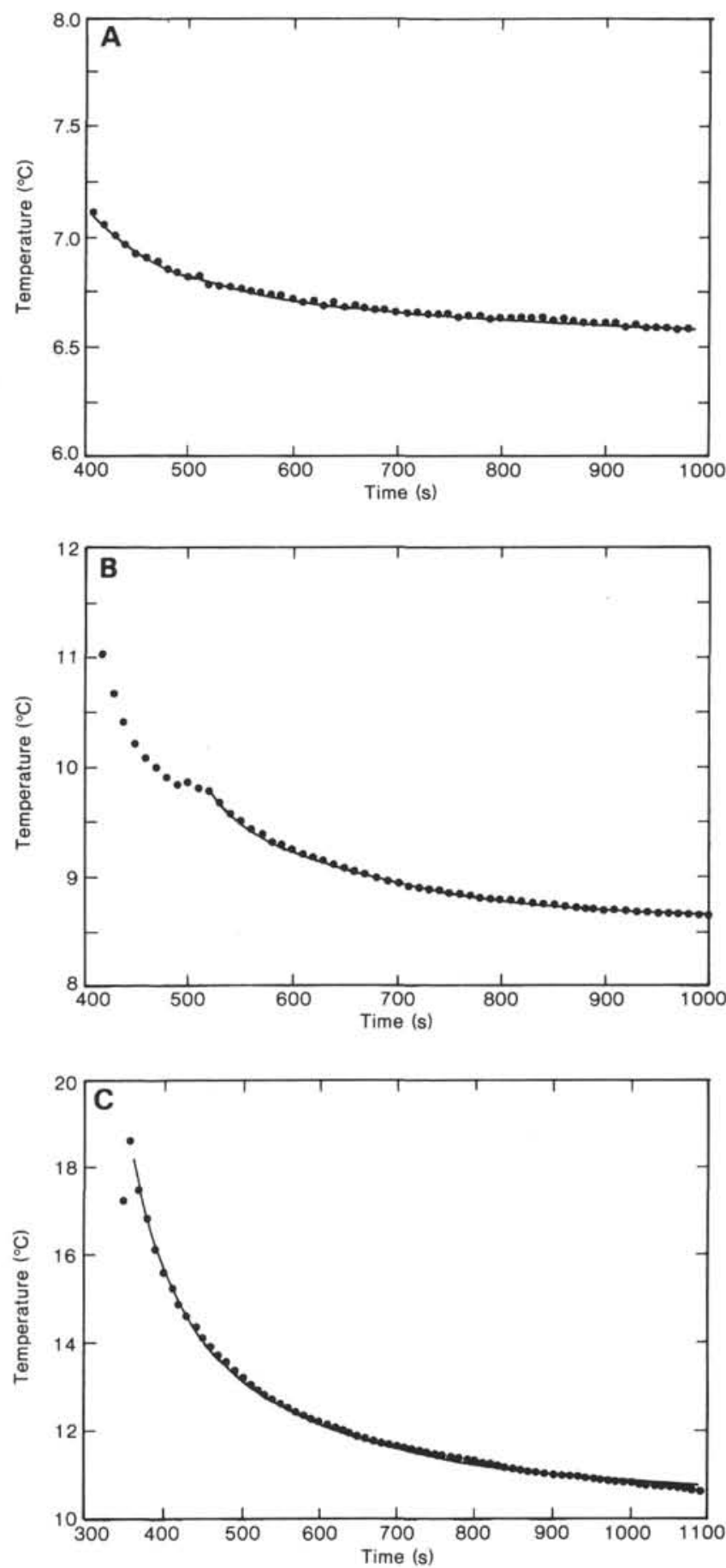

Figure 4. Temperature decay data (points) and corresponding best-fit theoretical solution (solid line) for Site 587 . A. $31.9 \mathrm{~m}$ depth, B. $70.3 \mathrm{~m}$ depth, C. $108.7 \mathrm{~m}$ depth.

The WHOI instrument package was deployed for a third time at a depth of $108.7 \mathrm{~m}$. The actual data and the theoretical fit are illustrated in Figure 4C. The associated residual error in this case is 0.068 and an in situ temperature of $8.65^{\circ} \mathrm{C}$ is predicted.

The uncertainties in estimating the in situ temperatures can best be considered by applying reasonable constraints to the theoretically derived results. In the three cases discussed previously, the actual temperatures are 
slightly less than the theoretical ones near the end of the recorded decay curve. Horai employs a two-dimensional model in his analysis, thus assuming that all conductive heat transfer takes place in the radial direction. In reality, however, some degree of axial cooling probably occurs at the base of the cutting shoe, thereby causing temperatures to fall more rapidly than theory has predicted. Hence, the theoretically derived in situ temperatures are likely to be slightly less than the actual ones. These former values are considered to be the lower bounds of the in situ temperature estimates. An upper bound can be conservatively estimated as being the last value observed during the recorded temperature decay. Thus, appropriate ranges of uncertainty can be attached to the estimated in situ temperatures.

Table 2 summarizes the successful geothermal measurements, with the sub-bottom depths obtained from the drillers' logs. The heat flow instrument was immediately lowered into the existing hole during the coring operation and was never permitted to reach thermal equilibrium at the sediment-seawater interface. Therefore, the bottom water temperature was not directly measured at this site. Nevertheless, nearby historical hydrographic data obtained from National Oceanographic Data Center listings give a value of about $4.1 \pm 0.1^{\circ} \mathrm{C}$ at a depth of $1115 \mathrm{~m}$. These data show no observable $\left(\leq 0.1^{\circ} \mathrm{C}\right)$ long-term variability over the period ranging from approximately 1960 to 1980 .

A weighted harmonic mean sediment thermal conductivity was calculated for each depth interval over which the geothermal gradient was determined. A particular sediment porosity has a thermal conductivity value associated with it, and the harmonic means were weighted corresponding to the porosity profile of Hole 587 presented by Morin (this volume). The degrees of uncertainty in estimating these quantities are stated in the footnotes to Table 2.

For purposes of computing thermal gradients through the sediment column across the pertinent depth intervals, assumptions are made regarding the designated temperature constraints. Since the theoretical fits shown in Figure 4 are in close agreement with the actual data, it is anticipated that the true in situ temperature will be much closer to $T_{\min }$, than to $T_{\max }$. The following equation is arbitrarily chosen as a subjective approximation to the actual temperature.

$$
\mathrm{T}_{\text {estimated }}=\mathrm{T}_{\min .}+\mathrm{C}\left(\mathrm{T}_{\max .}-\mathrm{T}_{\min .}\right)
$$

where $\mathrm{C}=$ constant $=0.20$. The exact value of $\mathrm{C}$ does not significantly affect the final temperature results except at the deepest depth, where the difference between $\mathrm{T}_{\max }$ and $\mathrm{T}_{\min }$ is greatest. Values of estimated temperatures are included in Table 2 and a plot of the temperature profile for Site 587 is presented in Figure 5.

\section{DISCUSSION}

Site 587 is located at $21^{\circ} 11.9^{\prime} \mathrm{S}, 161^{\circ} 20.0^{\prime} \mathrm{E}$ on the Lansdowne Bank. This geologic feature represents the northernmost part of the Lord Howe Rise and is bordered by the Lord Howe Basin to the west and the New Caledonia Basin to the east. This particular section of the southwest Pacific has a complex tectonic setting, with numerous crustal extensions and discontinuities. Lapouille (1976) has categorized the Lord Howe Rise based upon magnetic variations and crustal thickness (Officer, 1955). Seismic surveys of the New Caledonian margins reveal transitional seismic structures that lie between the proper oceanic domain of the central Pacific and the continental domain forming Australia (Dubois et al., 1974); it is believed that the region that encompasses the Lord Howe Rise and Site 587 probably has a thinned continental structure. Geophysical studies indicate that this zone was detached from Australia by the opening of the Tasman Sea during the Late Cretaceous between 60 and 80 m.y. ago (Hayes and Ringis, 1973). Maestrichtian sediments and rocks recovered from DSDP Sites 207 and 208, also located on the Lord Howe Rise, seem to confirm this age (Burns et al., 1973; Webb, 1973).

It is thus assumed that the crustal age at Site 587 is no younger than Late Cretaceous (65 m.y.) and probably around 80 m.y. Parsons and Sclater (1977) demonstrate that heat flow of normal seafloor can be estimated from crustal age by utilizing the following equation.

$$
q(t)=473 / t^{1 / 2}
$$

\begin{tabular}{|c|c|c|c|c|c|c|c|c|}
\hline Core & $\begin{array}{c}\text { Depth } \\
\text { (m) }\end{array}$ & $\underset{\left({ }^{\circ} \mathrm{C}\right)}{\mathrm{T}_{\max }}$ & $\begin{array}{l}\mathrm{T}_{\min } . \\
\left({ }^{\circ} \mathrm{C}\right)\end{array}$ & $\begin{array}{l}\mathrm{T}_{\text {est }}{ }^{\mathrm{a}} \\
\left({ }^{\circ} \mathrm{C}\right)\end{array}$ & $\begin{array}{l}\text { Thermal } \\
\text { gradient } \\
\left({ }^{\circ} \mathrm{C} / \mathrm{m}\right)\end{array}$ & $\begin{array}{l}\text { Thermal }^{\mathrm{b}} \\
\text { cond. } \\
\left(\mathrm{W} / \mathrm{m}^{\circ} \mathrm{C}\right)\end{array}$ & $\begin{array}{c}\text { Heat }^{c} \\
\text { flow } \\
\left(\mathrm{mW} / \mathrm{m}^{2}\right)\end{array}$ & $\begin{array}{c}\text { Heat }^{\mathrm{d}} \\
\text { flow-avg. } \\
\left(\mathrm{mW} / \mathrm{m}^{2}\right)\end{array}$ \\
\hline Seafloor & 0 & - & - & $4.1 \pm 0.1$ & \multirow{3}{*}{$\begin{array}{l}0.074 \pm 0.003 \\
0.044 \pm 0.001\end{array}$} & \multirow{3}{*}{$\begin{array}{l}1.06 \pm 0.08 \\
1.39 \pm 0.11\end{array}$} & \multirow{3}{*}{$\begin{array}{l}78.4 \pm 7.1 \\
61.2 \pm 5.1\end{array}$} & \multirow{4}{*}{$56.9 \pm 5.2$} \\
\hline 4 & 31.9 & 6.57 & 6.42 & $6.45 \pm 0.01$ & & & & \\
\hline 8 & 70.3 & 8.64 & 8.00 & $8.13 \pm 0.02$ & & & & \\
\hline 12 & 108.7 & 10.74 & 8.65 & $9.08 \pm 0.04$ & $0.025 \pm 0.001$ & $1.39 \pm 0.11$ & $34.8 \pm 3.1$ & \\
\hline
\end{tabular}

Table 2. Summary of geothermal data for Site 587.

Note: Dashes indicate that no measurement was made.

a Uncertainties are subjective estimates based upon accuracy of theoretical fit.

${ }^{b}$ Uncertainty includes standard experimental error of \pm 4 and $\pm 4 \%$ possible systematic error (weighted harmonic mean).

c Uncertainty computed as RMS sum of errors in thermal gradient and conductivity.

d Uncertainty computed as weighted RMS sum of interval heat flow errors. 


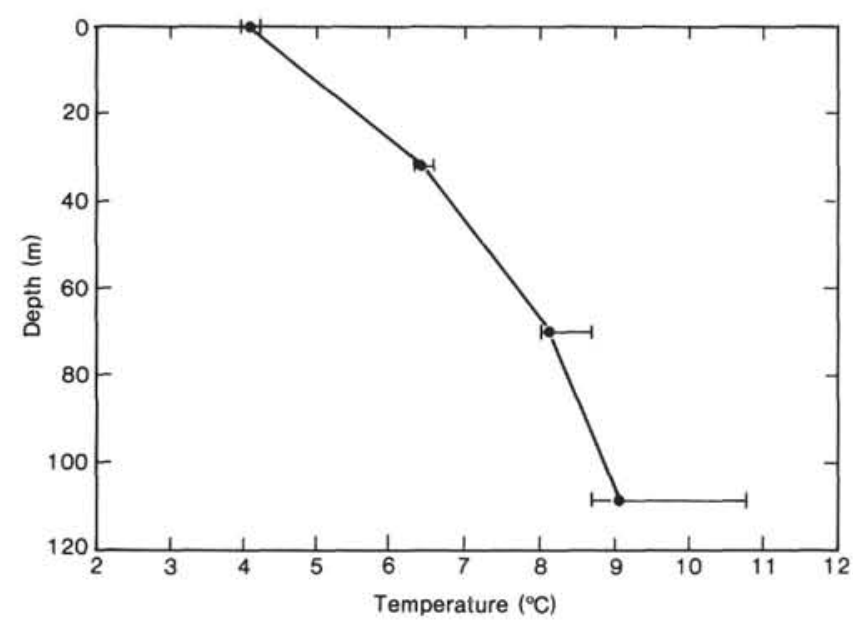

Figure 5. Plot of temperature versus sub-bottom depth for Site 587.

where $q(t)=$ heat flow as a function of time $\left(\mathrm{mW} / \mathrm{m}^{2}\right)$ and $t=$ age (m.y.)

The associated heat flow predicted for 80-m.y. basement is $53.0 \mathrm{~mW} / \mathrm{m}^{2}$. This theoretical value is in very good agreement with the average heat flow presented in Table 2, computed over the entire $108.7-\mathrm{m}$ depth interval as being $56.9 \mathrm{~mW} / \mathrm{m}^{2}$. There are relatively few heat flow data reported in the literature for this area from which to compare results. Sclater et al. (1972) have reported a heat flux of $42.8 \mathrm{~mW} / \mathrm{m}^{2}$ at a site $230 \mathrm{~km}$ to the east, nearer New Caledonia; Von Herzen (1973) has measured a value of $82.2 \mathrm{~mW} / \mathrm{m}^{2}$ at DSDP Site 209 , approximately $900 \mathrm{~km}$ to the northwest near the Coral Sea Basin.

The temperature profile depicted in Figure 5 is nonlinear. This curvature, although compensated somewhat by changes in thermal conductivity, translates into a nonuniform heat flow distribution with depth. The phenomenon of nonlinear temperature profiles has been vigorously investigated over the past few years (Langseth and Herman, 1981; Anderson et al., 1979; Abbott et al., 1981), although no adequate explanation has been presented yet for this behavior. Factors such as upward percolation of pore fluid through the sedimentary column, changes in bottom water temperature, and variations in thermal conductivity have been suggested as possible causes for the curved temperature profiles. In many cases concerned with marine studies, however, consideration of these factors has yielded inadequate or contradictory explanations.

If it is assumed that the temperatures determined at the two deepest points approach a linear, steady-state distribution, an associated geothermal gradient of $0.020^{\circ} \mathrm{C} /$ $\mathrm{m}$ can be approximated, with a corresponding steadystate bottom water temperature of $6.91^{\circ} \mathrm{C}$. In order to justify the temperature profile depicted in Figure 5 to be caused by variations in bottom water temperature, a sudden temperature decrease of about $2.9^{\circ} \mathrm{C}$ would have to have occurred and have been maintained over the past 100 years. These calculations are computed from the conduction equations for a semi-infinite solid presented by Carslaw and Jaeger (1978, p. 63) and are based on a step change of water temperature superimposed on a medium with uniform thermal diffusivity. Whereas small fluctuations in bottom water temperature may be expected at this site because of the relatively shallow water depth, the magnitude of the deviation required to properly explain the temperature distribution seems unlikely.

Vertical water advection through the sediment column also may produce nonlinear temperature profiles. When the one-dimensional energy balance described by Bredehoeft and Papadopulos (1965) for a medium with uniform thermal properties is applied to the three sediment temperatures listed in Table 2, the upward fluid velocity necessary to generate the resulting profile is computed to the $5.93 \times 10^{-7} \mathrm{~cm} / \mathrm{s}$. Unfortunately, permeability has not been determined for the sediments at this site. The material was relatively coarse grained, making retrieval with the HPC difficult. The sediments consisted mostly of skeletal silty sands, composed of corals, calcareous algae, and foraminifers. Because of the coarse grain size and absence of clays, it is anticipated that permeabilities are high. Average porosity through the sediment column is estimated at $60 \%$ from the porosity profile of Site 587 presented by Morin (this volume).

Bryant et al. (1975) have classified marine sediment permeabilities in terms of clay content and grain size. For silts and clays that have a significant sand-size fraction, permeability is roughly estimated to be on the order of $10^{-7} \mathrm{~cm} / \mathrm{s}$ at a porosity of $60 \%$. Robertson (1967) has measured the permeability of an aragonitic sediment during compaction. His results show a permeability on the order of $10^{-5} \mathrm{~cm} / \mathrm{s}$ at a porosity of $60 \%$. It is difficult to assign a reliable permeability to these Site 587 sediments in light of the wide range of values presented in the literature. For our purposes in this general analysis, however, it is assumed that sediment permeability is on the order of $10^{-6} \mathrm{~cm} / \mathrm{s}$. The corresponding hydraulic gradient necessary to generate an upward velocity of $5.93 \times 10^{-7} \mathrm{~cm} / \mathrm{s}$ is, thus, on the order of 0.1 .

$$
v=B i
$$

where $v=$ fluid velocity $(\mathrm{cm} / \mathrm{s}), B=$ sediment permeability $(\mathrm{cm} / \mathrm{s})$, and $i=$ hydraulic gradient (dimensionless).

The simple diagram of Figure 6 shows water percolating up through a sediment sample as it travels from points $\mathrm{A}$ to $\mathrm{C}$. One-dimensional flow conditions and a uniform permeability are assumed throughout the specimen. We wish to determine the hydraulic gradient necessary to achieve a "quick condition" (no effective stress) at the bottom of the specimen (point B). Conceptually, the height $h_{2}$ is gradually increased until the force pushing water up through the sample becomes so great that there is no longer an effective stress in the sediment at point B (i.e., no grain-to grain contacts, with particles suspended in fluid). The threshold value of this height $h_{2}$ is determined as follows:

$$
\sigma=\sigma^{\prime}+\mathrm{u}
$$

at point $\mathrm{B}, \sigma^{\prime}=0, \sigma=\mathrm{u}-$ from (1) 


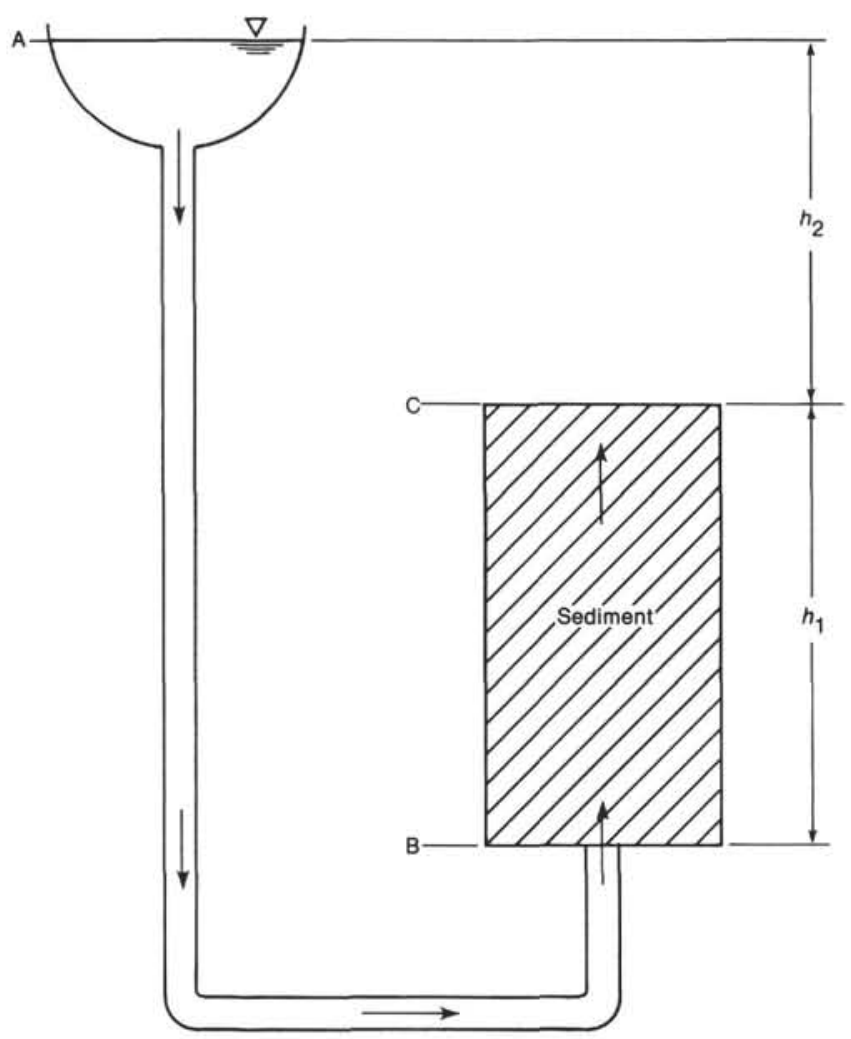

Figure 6. Schematic diagram illustrating water moving up through a sediment sample under a hydraulic pressure gradient. Sketch is used to determine the hydraulic gradient necessary to produce a "quick condition" (see text).

$$
\begin{gathered}
\mathrm{u}=\gamma_{W}\left(h_{1}+h_{2}\right) \\
\sigma=\left(\gamma_{W}+\gamma_{b}\right) h_{1}
\end{gathered}
$$

where $\sigma=$ total stress, $\sigma^{\prime}=$ effective stress, $\mathrm{u}=$ pore water pressure, $\gamma_{W}=$ unit weight of water, and $\gamma_{b}=$ unit weight of sediment in water.

Equating (2) and (3),

$$
\begin{aligned}
\gamma_{W}\left(h_{1}+h_{2}\right) & =\left(\gamma_{W}+\gamma_{b}\right) h_{1} \\
\gamma_{W} h_{2} & =\gamma_{b} h_{1} \\
h_{2} / h_{1} & =\gamma_{b} / \gamma_{W} \\
& =\text { threshold hydraulic gradient } i_{\text {quick }} .
\end{aligned}
$$

But

$$
\begin{aligned}
& \gamma_{b}=\gamma_{W}(G-1)(1-\Phi) \\
& \text { (from Lambe and Whitman, 1969) }
\end{aligned}
$$

where $G=$ specific gravity of solids, $\Phi=$ porosity.

$$
\therefore i_{\text {quick }}=(G-1)(1-\Phi)=0.66
$$

assuming $G=2.65$ and $\Phi=0.60$.
Thus, a hydraulic gradient larger than 0.66 will cause a "quick condition" on the seafloor. This value is on the same order as that determined necessary to produce the calculated nonlinear temperature profile. Without knowing the permeability more accurately, firm conclusions cannot be reached. If the required gradient is larger than 0.66 , this solution is not valid physically. If the gradient needed to generate the appropriate fluid flow is smaller than the threshold gradient, upward percolation through the sediment column may provide a viable explanation for the temperature distribution. This latter condition seems unlikely, however, since an upward flow of $5.93 \times$ $10^{-7} \mathrm{~cm} / \mathrm{s}$ implies a local surface heat transfer of about $155 \mathrm{~mW} / \mathrm{m}^{2}$ (Anderson et al., 1979). This value is much higher than all surface heat flow measurements reported for this region and is also much larger than the value calculated from the heat flow versus age relationship presented earlier.

An examination of the effects of variable bottom water temperature and pore fluid movement fails to provide a convincing solution as to the cause of the nonlinear temperature profile at Site 587. Von Herzen (1973) presented a similar profile at Site 206 in the New Caledonia Basin. The large error bar in the predicted temperature at the 108.7-m depth, however, makes it difficult to be certain about the significance of curvature in the profile. Better resolution of this deepest temperature is required before a distinct nonlinear temperature distribution can be confidently assumed. It is to be hoped that a revised, three-dimensional version of Horai's theoretical formulation will permit a re-evaluation of the WHOI instrument data at a future time.

\section{ACKNOWLEDGMENTS}

We are grateful to the co-chief scientists of Leg 90, J. Kennett and C. von der Borch, for the opportunity to pursue a heat flow program and make these measurements.

\section{REFERENCES}

Abbott, D., Menke, W., Hobart, M., and Anderson, R., 1981. Evidence for excess pore pressures in southwest Indian Ocean sediments. J. Geophys. Res., 86:1813-1827.

Anderson, R. N., Hobart, M. A., and Langseth, M. G., 1979. Geothermal convection through oceanic crust and sediments in the Indian Ocean. Science, 204:828-832.

Bredehoeft, J. D., and Papadopulos, J. S., 1965. Rates of vertical groundwater movement estimated from the Earth's thermal profile. Water Res. Res., 2:325-328.

Bryant, W. R., Hottman, W., and Trabant, P., 1975. Permeability of unconsolidated and consolidated marine sediments, Gulf of Mexico. Mar. Geotech., 1:1-13.

Burns, R. E., Andrews, J. E., et al., 1973. Init. Repts. DSDP, 21 : Washington (U.S. Govt. Printing Office).

Carlsaw, H. S., and Jaeger, J. C., 1978. Conduction of Heat in Solids (2nd Ed.): Oxford (Clarendon Press).

Chaney, R. C., Ramanjaneya, G., Hencey, G., Kanchanastit, P., and Fang, H. Y., 1983. Suggested test method for determination of thermal conductivity of soil by thermal-needle procedure. Geotech. Testing J., 6:220-225.

Dubois, J., Ravenne, C., Aubertin, A., Louis, J., Guillaume, R., Launay, J., and Montadert, L., 1974. Continental margins near New Caledonia. In Burk, C. A., and Drake, C. L. (Eds.), The Geology of Continental Margins: New York (Springer-Verlag), pp. 521-535.

Hayes, D. E., and Ringis, J., 1973. Seafloor spreading in the Tasman Sea. Nature, 243:454-458. 


\section{R. H. MORIN, R. P. VON HERZEN}

Lambe, T. W., and Whitman, R. V., 1969. Soil Mechanics: New York (J. Wiley and Sons).

Langseth, M. G., and Herman, B. M., 1981. Heat transfer in the oceanic crust of the Brazil Basin. J. Geophys. Res., 86:10805-10819.

Lapouille, A., 1976. Magnetic surveys over the rises and basins in the South-West Pacific. Int. Symp. Geodynamics in South-West Pccific, Noumea (New Caledonia), 15-28.

Macdonald, K., and Simmons, G., 1972. Temperature coefficient of the thermal conductivities of ocean sediments. Deep-Sea Res., 19: 669-671.

Morin, R. H., and Silva, A. J., 1984. The effects of high pressure and high temperature on some physical properties of ocean sediments. J. Geophys. Res., 89;511-526.

Officer, C. B., 1955. Southwest Pacific crustal structure. Trans. Am. Geophys. Union, 36:449-459.

Parsons, B., and Sclater, J. G., 1977. An analysis of the variation of ocean floor bathymetry and heat flow with age. J. Geophys. Res., $82: 803-827$.

Ratcliffe, E. H., 1960. The thermal conductivities of ocean sediments. J. Geophys. Res., 65:1535-1541.

Robertson, E. C., 1967. Laboratory consolidation of carbonate sediment. In Richards, A. F. (Ed.), Marine Geotechnique: Urbana (Univ. of Ill. Press), pp. 118-127.

Sclater, J. G., Ritter, U. G., and Dixon, F. S., 1972. Heat flow in the southwestern Pacific. J. Geophys. Res., 77:5697-5704.

Von Herzen, R. P., 1973. Geothermal measurements, Leg 21. In Burns, R. E., Andrews, J. E., et al., Init. Repts. DSDP, 21: Washington (U.S. Govt. Printing Office), 443-457.

Von Herzen, R. P., and Maxwell, A. E., 1959. The measurement of thermal conductivity of deep-sea sediments by a needle-probe method. J. Geophys. Res., 64:1557-1563.

Webb, P. N., 1977. Upper Cretaceous-Paleocene foraminifers from Site 208 (Lord Howe Rise, Tasman Sea). In Burns, R. E., Andrews, J. E., et al., Init. Repts. DSDP, 21: Washington (U.S. Govt. Printing Office), 541-574.

Yokota, T., Kinoshita, H., and Uyeda, S., 1980. New DSDP downhole temperature probe utilizing ICRAM (Memory) elements. Bull. Earthquake Res. Inst., 55:75-88.

Date of Initial Receipt: 14 May 1984

Date of Acceptance: 20 November 1984

\section{APPENDIX}

Sediment Thermal Conductivity Corrections for In Situ Pressure and Temperature

Pressure:

assume shipboard thermal conductivity $=1.00 \mathrm{~W} / \mathrm{m}^{\circ} \mathrm{C}$

water depth $=1100 \mathrm{~m}$

(from Morin and Silva, 1984)

assume sediment porosity $=0.70$

$\begin{array}{ll}\text { pressure corrected }= & \text { therm. cond. } \\ \text { therm. cond. } & \text { at } 1 \mathrm{~atm}\end{array}$

pressure correction $=\left(\frac{0.0042 \mathrm{~W}}{\mathrm{~m}^{\circ} \mathrm{C}}\right)\left(\frac{1100 \mathrm{~m}}{1000 \mathrm{~m}}\right)=\frac{0.0046 \mathrm{~W}}{\mathrm{~m}^{\circ} \mathrm{C}}$

$\%$ correction $=\frac{+0.0046}{1.00}=+0.46 \%$

(from Ratcliffe, 1960)

$1 \%$ increase in thermal conductivity per 1000 fathoms $(1830 \mathrm{~m})$ water depth

$\%$ correction $=(0.01)\left(\frac{1100 \mathrm{~m}}{1830 \mathrm{~m}}\right)=+0.60 \%$

Temperature:

assume shipboard temperature $=22^{\circ} \mathrm{C}$

assume in situ temperature $=6^{\circ} \mathrm{C}$

(from Macdonald and Simmons, 1972)

therm. cond. correction $=\left(\frac{0.193 \%}{{ }^{\circ} \mathrm{C}}\right)\left(6^{\circ} \mathrm{C}-22^{\circ} \mathrm{C}\right)$

$\%$ correction $=-3.09 \%$

Total correction $=+0.46 \%$ (pressure) $-3.09 \%$ (temperature)

$$
=-2.63 \%
$$

